Article

\title{
Versatile Polypropylene Copolymers from a Pilot-Scale Spheripol II Process
}

\author{
Xiong Wang *(D), Renwei Xu, Wenqian Kang, Jie Fan, Xiaoyu Han and Yunbo Xu \\ Lanzhou Petrochemical Research Center, Petrochemical Research Institute, PetroChina, Lanzhou 730060, China; \\ xurenwei@petrochina.com.cn (R.X.); kangwenqian@petrochina.com.cn (W.K.); fanjie3@petrochina.com.cn (J.F.); \\ hanxiaoyu@petrochina.com.cn (X.H.); xuyunbo@petrochina.com.cn (Y.X.) \\ * Correspondence: wangxiong1@petrochina.com.cn
}

Received: 22 February 2020; Accepted: 25 March 2020; Published: 30 March 2020

check for updates

\begin{abstract}
Polypropylene (PP) is one of the most widely used polymers. In this paper, three types of PPs including random PP, impact PP, and impact PP with high clarity, were prepared through a $75 \mathrm{~kg} / \mathrm{h}$ pilot-scale Spheripol II process. The three produced PPs were produced by the selection or combination the two loops and gas phase reactor and controlling the comonomer and hydrogen concentrations. The three prepared PPs then were pelleted with the clarified nucleating agent NX 8000 and tested for mechanical, thermal, and optical properties. Their molecular structures and rubber phase size were also investigated by GPC, ${ }^{13} \mathrm{C}$ NMR, temperature rising elution fractionation (TREF), XRD, SEM analysis, etc. The results showed that the random PP (PP-1) and the impact PP with high clarity (PP-3) obtained excellent optical transparency with a haze of $12.5 \%$ and $13.5 \%$ due to their small rubber phase size (roughly $\leq 100 \mathrm{~nm}$ ), while the impact PP (PP-2) obtained bad transparency with a haze of $98.8 \%$ due to the large rubber phase size (about $1 \mu \mathrm{m}$ ) caused by the poor thermal compatibility with the PP matrix. The rubber phase content and ethylene/propylene sequence distributions of the three PPs varied much and resulted in different impact strengths and stiffness properties. PP-2 had a high impact strength of $14.5 \mathrm{~kJ} / \mathrm{m}^{2}$ due to the rubber phase generated in the gas phase reactor. Except for the optical transparency, PP-3 gained stiffness and toughness, with $914 \mathrm{MPa}$ of flexural modulus and $25.1 \mathrm{~kJ} / \mathrm{m}^{2}$ of impact strength due to the unique molecular structure of its rubber phase.
\end{abstract}

Keywords: polypropylene polymerization; Spheripol process; random PP (RPP); impact PP; impact PP with high clarity

\section{Introduction}

Since the discovery of the Ziegler-Natta (Z-N) catalyst in the 1950s, the production of polyolefins with various chain microstructures and properties has continuously grown with the rapid development of catalyst technology combined with polymerization innovation [1-10]. Polypropylene (PP) is undoubtedly one of most used and robust material fields in the production and consumption market globally [11-15]. Its properties vary from plastic to elastomer, and it is used in a wide range of applications, from packaging to household electric appliances, medical, lightweight engineering plastics for automobiles, construction, equipment, and facilities industries. The global production of PP was about 56 million tons in 2016 and is estimated to reach 80 million tons by 2022 [16].

The first major breakthrough in the Z-N catalysts in 1968 was promoted by Montedison (now LyondellBasell) and Mitsui with the discovery of the milled $\mathrm{MgCl}_{2}$ support for ethylene polymerization [17-19]. This technology was adopted by the extra addition of internal and external electron donors to improve the isotacticity of PP without catalyst activity in the PP industry in the 
1970s, which led to the third-generation of PP catalysts, eliminating the need for catalyst residue removal, but the atactic content was still too high.

The second breakthrough appeared with "the reactor granule technology" (RGT) in the fourth-generation catalysts in the 1980s. When propylene polymerization occurred in the RGT catalyst, the catalyst grew into a polymer particle with active sites within it, so both the catalyst and the polymer particle could act as the reactor during the polymerization.

The heterogeneous catalysis was mainly based on the active $\mathrm{MgCl}_{2}$ in a spherical granule or spherical form with $\mathrm{MgCl}_{2}$ or $\mathrm{Mg}\left(\mathrm{OC}_{2} \mathrm{H}_{5}\right)_{2}$ as a starting material [20-23]. Those granule or spherical $\mathrm{MgCl}_{2}$-based PP catalysts typically had a higher and longer activity and were capable of tuning the molecular distribution by the selection of internal electron donors, allowing morphology replication of the support particle in the process of polymerization; therefore, substantial process simplification was made possible. Then, the innovation in Z-N PP catalyst in recent decades was mainly focused on alternative electron donors (including internal and external donors) to develop PP with specific molecular microstructures or even higher activity [24-29].

Along with the development of PP catalyst technology, a series of PP polymerization processes was developed and commercialized successfully. Owing to the RGT catalysts, the revolutionary development of PP-based production processes also took place, such as Spheripol, Novelen, Spherizone, Unipol, Catalloy, etc. [16,30-32], which made it possible to generate multiphase alloys and blends directly in multiple reactors, producing high-performance materials not available with conventional technologies.

In this work, a spherical $\mathrm{MgCl}_{2}$-based Z-N catalyst was used in $75 \mathrm{~kg} / \mathrm{h}$ pilot-scale Spheripol II equipment. Generally, isotactic polypropylene (iPP) and random copolymer polypropylene (RPP) can be produced in the first two loops, while impact PP can be produced by the first two loops and the third gas phase reactor. By tuning the polymerization conditions, three types of $\mathrm{PP}$, including an ethylene/propylene/1-butene (EPB) random copolymer, an impact ethylene/propylene (E/P) copolymer, and a transparent and impact polypropylene, are generated in the Spheripol II process. The three types of PP are characterized by GPC, ${ }^{13} \mathrm{C}$ NMR, temperature rising elution fractionation (TREF), XRD, SEM analysis, etc. The results show that the three PPs possess different molecular chain microstructures, which result in various mechanical, thermal, and optical properties.

\section{Materials and Method}

\subsection{Materials}

Ethylene, propylene, 1-butene, and nitrogen gas (polymerization grade, $\geq 99.99 \%$ ) were provided by Lanzhou Petrochemical Company, PetroChina (Lanzhou, China). Three types of polypropylene (PP) copolymers were prepared through different process conditions via $75 \mathrm{~kg} / \mathrm{h}$ pilot-scale Spheripol II process equipment at Lanzhou Petrochemical Research Center, Petrochemical Research Center, PetroChina. A conventional Z-N catalyst (provided by Lanzhou Petrochemical Company, PetroChina) was used in the polymerization. Antioxidant 1010, antioxidant 168, calcium stearate, and nucleating agent Millad NX8000 were donated by Lanzhou Petrochemical Company as PP additives.

\subsection{Polymerization Process and Prepared Copolymers}

Propylene and ethylene polymerization were conducted in a $75 \mathrm{~kg} / \mathrm{h}$ pilot-scale Spheripol II process. The schematic PP process of Spheripol II is shown in Figure 1. As seen in Figure 1, the Spheripol II process consisted of two loops and a gas phase stirring reactor. Generally, propylene homopolymerization or random polymerization with ethylene or $\alpha$-olefin could be conducted in the two loops, while block copolymerization was only conducted in the gas phase reactor. 


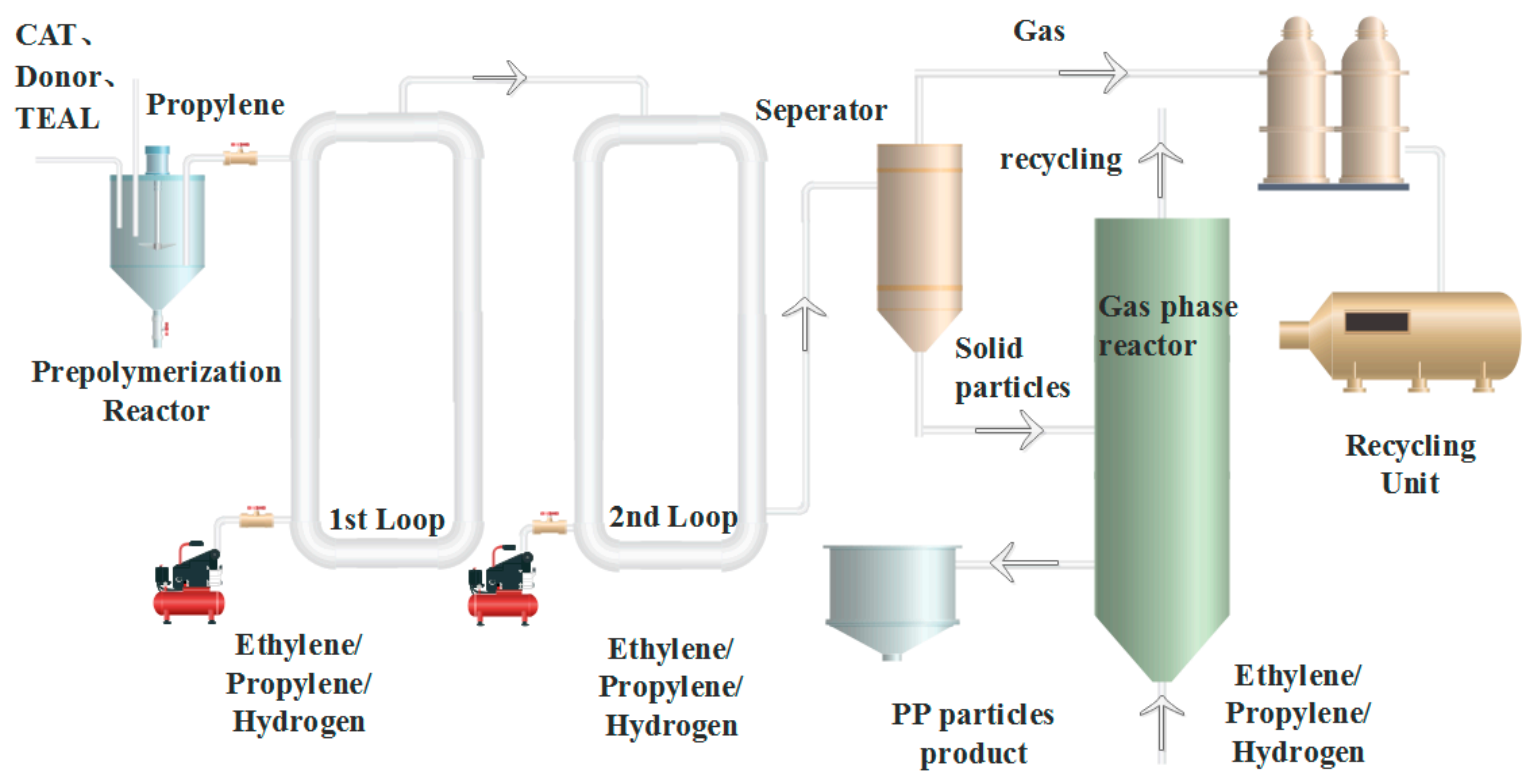

Figure 1. The schematic process of Spheripol II. CAT: Z-N catalyst, TEAL: triethylaluminum, Donor: cyclohexyl methyl dimethoxysilane.

The catalyst used was $\mathrm{TiCl}_{4}$ supported on $\mathrm{MgCl}_{2}$ with triethylaluminum cocatalyst, diisobutyl phthalate as the internal electron donor, and cyclohexyl methyl dimethoxysilane as the external donor. Three types of PP were prepared according to different polymerization processes and conditions, and they are listed in Table 1. PP-1 was prepared through random copolymerization of propylene with ethylene and 1-butene, and the gas phase reactor was not used. PP-2 was prepared through random copolymerization of propylene and ethylene in the two loops, combined with block copolymerization of propylene and ethylene in the gas phase reactor. PP-3 was prepared through propylene homopolymerization in the first two reactors combined with block polymerization of propylene and ethylene with a certain concentration of hydrogen. Then, the prepared PP particles were mixed with a certain amount of additives in a high-speed mixer and extruded and made into pellets using a twin-screw extruder (ZSE-34, LEISTRTIZE, Wiesbaden, Germany).

Table 1. Polymerization comonomers used in the reactors of the Spheripol process for the preparation of PP-1/PP-2/PP-3.

\begin{tabular}{lccc}
\hline Sample & $\mathbf{1}^{\text {st }}$ Loop & $\mathbf{2}^{\text {nd }}$ Loop & Gas-Phase Reactor \\
\hline PP-1 & propylene/ethylene/1-butene/hydrogen & propylene/ethylene/hydrogen & - \\
PP-2 & propylene/ethylene/hydrogen & propylene/ethylene/hydrogen & propylene/ethylene/hydrogen \\
PP-3 & propylene/hydrogen & Propylene/hydrogen & propylene/ethylene/hydrogen \\
\hline
\end{tabular}

\subsection{Characterization}

\subsubsection{Mechanical Test}

The tensile and flexural properties were tested on an Instron 5566 universal testing machine (Instron, Norwood, MA, USA) at room temperature $\left(23^{\circ} \mathrm{C}\right)$ according to GB/T 1040.1-2006 and GB/T 9341-2008, respectively. A CEAST 7028 (CEAST, Turin, Italy) was used to test the melting index according to GBT 3682, and the heat distortion temperature (HDT) was tested on an XRW-300UA (Zhonghangshidai, Beijing, China) according to GB/T 1634.1-2004. The notched Izod impact was carried out on a 92T Pendulum impact tester (TINIUS OLSEN, Philadelphia, PA, USA) at $23^{\circ} \mathrm{C}$ according to GB/T 1843-2008. All test specimens were kept at $23^{\circ} \mathrm{C}$ for at least $24 \mathrm{~h}$ before the test, and the average value was taken from at least 5 tests. 


\subsubsection{IR, DSC, and XRD Analysis}

IR analysis was performed on a NEXUS 670 FT-IR (Nicolet, Glendale, WI, USA). Film samples of about $10-20 \mu \mathrm{m}$ were prepared for testing at $180{ }^{\circ} \mathrm{C}$ and under $10 \mathrm{MPa}$ pressure. Differential scanning calorimetry (DSC) analysis was carried out on a DSC 214 Polyma instrument (NETZSCH, Selb, Germany). Seven to ten milligrams of sample were firstly heated from room temperature to $200{ }^{\circ} \mathrm{C}$ under a nitrogen atmosphere at a heating rate of $20^{\circ} \mathrm{C} / \mathrm{min}$, then cooled to $30^{\circ} \mathrm{C}$ at a cooling rate of $20^{\circ} \mathrm{C} / \mathrm{min}$ to eliminate the heat history of the sample. The melting and crystallization curves were obtained, respectively, when heating the samples to $200^{\circ} \mathrm{C}$ and cooling the samples to $30{ }^{\circ} \mathrm{C}$ at the same heating and cooling rate once again. Wide-angle X-ray diffraction (WXRD) was tested on a D8 ADVANCE diffractometer (Bruker, Karlsruher, Germany). A $1 \mathrm{~mm}$ thick sheet of the samples was used and scanned at $40^{\circ} \mathrm{C}$ and $4^{\circ} / \mathrm{min}$ under $\mathrm{Cu}-\mathrm{K} \alpha$ irradiation $(\lambda=0.154 \mathrm{~nm})$.

\subsubsection{GPC and ${ }^{13} \mathrm{CNMR}$ Analysis}

Gel permeation chromatography (GPC) was carried out on a GPC-IR instrument (Polymer Char, Valencia, Spain) at $135{ }^{\circ} \mathrm{C}$ using 1,2,4-trichlorobenzene (TCB) as the solvent with a sampling concentration of $3 \mathrm{mg} / \mathrm{mL}$ and a sampling rate of $1.0 \mathrm{~mL} / \mathrm{min}$. The ${ }^{13} \mathrm{C}$ NMR spectra of samples were recorded on a Bruker $500 \mathrm{MHz}$ NMR spectrometer (Breika, MA, USA) at $120{ }^{\circ} \mathrm{C}$ using o- $\mathrm{C}_{6} \mathrm{H}_{4} \mathrm{Cl}_{2} / \mathrm{o}-\mathrm{C}_{6} \mathrm{D}_{4} \mathrm{Cl}_{2}(50 \% \mathrm{v} / \mathrm{v})$ as the solvent. The ${ }^{13} \mathrm{C}$ NMR spectra were obtained with a $74^{\circ}$ flip angle, an acquisition time of $1.5 \mathrm{~s}$, and a delay of $4.0 \mathrm{~s}$.

\subsubsection{Solubility in Xylene and TREF Analysis}

Xylene soluble analysis was performed according to GB/T 24282-2009. A 2.0 g sample was dissolved in $100 \mathrm{~mL}$ xylene at $130^{\circ} \mathrm{C}$, then the solution was cooled to $25^{\circ} \mathrm{C}$ and sieved to remove the solid and obtain the soluble xylene by rotating evaporation. Temperature rising elution fractionation (TREF) was analyzed in a Model 200+ instrument (Polymer Char, Valencia, Spain). Standard conditions were used with $40 \mathrm{mg}$ in $20 \mathrm{~mL}$ of 1,2,4-trichlorobenzene (TCB), a crystallization rate of $0.5^{\circ} \mathrm{C} / \mathrm{min}$, and an elution rate of $1^{\circ} \mathrm{C} / \mathrm{min}$.

\subsubsection{Crystallization and Rubber Phase Morphology Observation}

Isothermal crystallization was observed through a polarized optical microscope (DM2500P, Leica, Weztlar, Germany) at $140^{\circ} \mathrm{C}$ for $5 \mathrm{~min}$. Scanning electron microscopy (SEM) was performed on an ULTRA plus field-emission electron microscope (FESEM, Zeiss, Oberkochen, Germany). The specimens were prepared by the cryogenic fracture of the injection molded bars under liquid nitrogen $(77 \mathrm{~K})$ for at least $10 \mathrm{~min}$ and then etched in xylene at room temperature for $24 \mathrm{~h}$ to remove the rubber phase. Then, the fracture surface was coated with a thin layer of gold-palladium in a vacuum before the observation of the surface morphology.

\section{Results and Discussion}

\subsection{Mechanical and Optical Results}

Generally, a series of additives including antioxidants, nucleating agents, acid absorbents, etc., was mixed with the PP powder to improve the overall performance of the final product. In this work, nucleating agent NX8000 was incorporated into the three PPs to evaluate their mechanical properties, as well as optical properties. As seen from Table 2, the mechanical properties of PP-1 could be improved dramatically when the amount of NX8000 was increased from $0 \mathrm{ppm}$ to $3000 \mathrm{ppm}$, with the impact strength increased from $3.5 \mathrm{~kJ} / \mathrm{m}^{2}$ to $6.5 \mathrm{~kJ} / \mathrm{m}^{2}$ and a flexural modulus from $891 \mathrm{MPa}$ to $1162 \mathrm{MPa}$. Moreover, the nonitol-based Millad NX 8000 exhibited an excellent clarifying effect by decreasing the size of spherulites and improved the transparency with the haze decreased from $45.1 \%$ to $12.5 \%$. 
Table 2. Mechanical analysis results of the PP materials.

\begin{tabular}{|c|c|c|c|c|c|c|c|c|c|c|}
\hline Entry & Sample & $\begin{array}{c}\text { *Millad } \\
\text { NX } 8000 \\
\text { ppm }\end{array}$ & $\begin{array}{l}\text { Melting } \\
\text { Index } \\
\text { g/10 min }\end{array}$ & $\begin{array}{c}\text { Flexural } \\
\text { Modulus } \\
\text { MPa }\end{array}$ & $\begin{array}{l}\text { Tensile } \\
\text { Yield } \\
\text { Stress } \\
\text { MPa }\end{array}$ & $\begin{array}{c}\text { Impact } \\
\text { Strength } \\
\mathrm{kJ} / \mathrm{m}^{2}\end{array}$ & $\begin{array}{c}\text { Heat } \\
\text { Distortion } \\
\text { Temperature } \\
{ }^{\circ} \mathrm{C}\end{array}$ & $\begin{array}{c}\text { Transmittance } \\
\%\end{array}$ & Haze\% & $\begin{array}{c}\text { Xc, } \\
\text { WAXD } \\
\%\end{array}$ \\
\hline 1 & $\begin{array}{l}\text { PP-1 } \\
(1-0)\end{array}$ & 0 & 11.6 & 891 & 23.4 & 3.5 & 67 & 88.6 & 45.1 & 52.3 \\
\hline 2 & $\begin{array}{l}\text { PP-1 } \\
(1-1)\end{array}$ & 1500 & 10.9 & 1005 & 26.7 & 4.8 & 70 & 88.5 & 40.6 & 55.6 \\
\hline 3 & $\begin{array}{l}\text { PP-1 } \\
(1-2)\end{array}$ & 2500 & 10.6 & 1139 & 28.2 & 6.0 & 74 & 87.1 & 17.8 & 59.9 \\
\hline 4 & $\begin{array}{l}\text { PP-1 } \\
(1-3)\end{array}$ & 3000 & 10.6 & 1162 & 28.3 & 6.5 & 76 & 87.1 & 12.5 & 62.3 \\
\hline 5 & PP-2 & 3000 & 10.8 & 739 & 19.6 & 14.5 & 69 & 73.3 & 98.8 & 51.1 \\
\hline 6 & PP-3 & 3000 & 8.4 & 914 & 25.2 & 25.1 & 62 & 84.2 & 13.5 & 62.4 \\
\hline
\end{tabular}

The three types of PP prepared from the pilot-scale Spheripol process equipment were also tested to evaluate their overall mechanical and optical performance using the same amount of NX 8000. As shown from Table 2, the melting index of three types of PP was well-controlled between 8 and $11 \mathrm{~g} / 10 \mathrm{~min}$, which endowed them a similar processability. PP-1 prepared from random copolymerization had the best stiffness with a flexural modulus of $1162 \mathrm{MPa}$ and a tensile yield stress of $28.3 \mathrm{MPa}$; however, its toughness was the lowest in terms of the impact strength of $6.5 \mathrm{~kJ} / \mathrm{m}^{2}$ without using the ethylene/propylene copolymerization in the third gas reactor. In contrast, when ethylene/propylene gas copolymerization was adopted for PP-2 and PP-3, they acquired excellent impact strength with that of PP-2 of $19.6 \mathrm{~kJ} / \mathrm{m}^{2}$ and of PP-3 of $25.1 \mathrm{~kJ} / \mathrm{m}^{2}$, with a compensation of stiffness for toughness. The heat distortion temperature (HDT) of PP- 1 was $76{ }^{\circ} \mathrm{C}$ due to its high stiffness. Although the flexural modulus of PP-3 (914 MPa) was much higher than PP-2 (739 MPa), the HDT of PP-3 $\left(62{ }^{\circ} \mathrm{C}\right)$ was lower than that of PP-2 $\left(69^{\circ} \mathrm{C}\right)$, which may be attributed to their different rubber phase sizes.

Despite the similar polymerization process of the combination of two loops and a gas reactor, the difference in the rubber phase size also led to the change of optical results: the haze of PP-3 (13.5\%) was lower than PP-2 (98.8\%) due to the smaller size of the rubber phase dispersed in PP-3 (we will discuss the rubber phase size later in detail). For transparent copolymers, the rubber phase and the spherulite sizes were normally below the half wavelength of the visible light to avoid strong light scattering. PP-1 had the best optical properties due to a lack of a rubber phase generated in the gas reactor. From Figure 2, we can observe that PP-1 and PP-3 had excellent transparency with a legible view of the underlying paper through a $1 \mathrm{~mm}$ thick sheet, while being illegible for PP-2, mainly due to its large rubber phase size. Typically, PP-3 not only offered a great stiffness-toughness balance, but excellent optical transparency, compared to PP-2 prepared through a similar process.
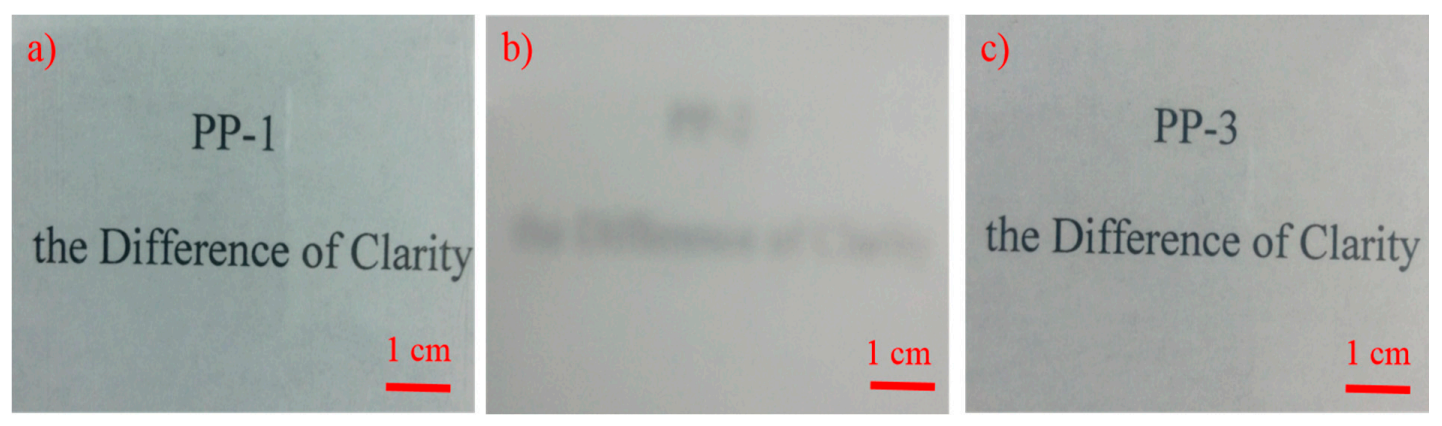

Figure 2. Digital photos comparing the transparency of various polymers (1 mm thick sheet). (a) PP-1; (b) PP-2; (c)PP-3. Three samples were determined with 3000 ppm NX 8000 as the nucleating agent. 


\subsection{Molecular Structure Analysis}

\subsubsection{Solubility in Xylene and IR Analysis}

The three PP materials prepared from different polymerization processes have different chemical compositions and xylene soluble fractions at $25^{\circ} \mathrm{C}$. The ethylene and 1-butene monomer content could be determined from IR spectrum according to [33,34]. The signal ranging from $4482 \mathrm{~cm}^{-1}$ to $3950 \mathrm{~cm}^{-1}$ of the PP matrix could be used as a calibration reference, when ethylene content was less than $8 \%$; the absorption peak signal from $758 \mathrm{~cm}^{-1}$ to $679 \mathrm{~cm}^{-1}$ could be adopted for the determination of the ethylene content; and the signal from $777 \mathrm{~cm}^{-1}$ to $679 \mathrm{~cm}^{-1}$ could be used when the ethylene content was above $8 \%$. The peak around $769 \mathrm{~cm}^{-1}$ could be used to characterize the 1-butene content. Therefore, the value of the peak area of ethylene or 1-butene from $4482 \mathrm{~cm}^{-1}$ to $3950 \mathrm{~cm}^{-1}$ of the PP matrix could be used to calculate the ethylene or 1-butene content by standard curves. The monomer contents and xylene soluble fraction results are listed in Table 3.

Table 3. Chemical composition of the pilot pellets and xylene soluble fraction at $25^{\circ} \mathrm{C}$.

\begin{tabular}{cccccc}
\hline Sample & $\begin{array}{c}\text { Ethylene } \\
\text { Content } \\
\text { (wt.\%) }\end{array}$ & $\begin{array}{c}\text { 1-Butene } \\
\text { Content (wt.\%) }\end{array}$ & $\begin{array}{c}\text { Xylene } \\
\text { Soluble at } \\
\mathbf{2 5}{ }^{\circ} \mathbf{C} \text { (wt.\%) }\end{array}$ & $\begin{array}{c}\text { Ethylene Content of } \\
\text { Soluble Fraction in } \\
\text { Xylene (wt.\%) }\end{array}$ & $\begin{array}{c}\text { Ethylene Content of } \\
\text { Non-Soluble } \\
\text { Fraction in Xylene } \\
\text { (wt.\%) }\end{array}$ \\
\hline PP-1 & $2.7-3.0$ & $1.1 \%$ & 4.8 & $12.0 \sim 14.2$ & $1.6 \sim 1.8$ \\
PP-2 & 8.0 & - & 15.2 & $34.7 \sim 35.4$ & $4.6 \sim 5.8$ \\
PP-3 & 4.9 & - & 12.2 & $24.6 \sim 25.0$ & $1.6 \sim 2.0$ \\
\hline
\end{tabular}

${ }^{*}$ a Determined by IR quantitative analysis.

The ethylene and 1-butene content in the ethylene/propylene/1-butene $(\mathrm{E} / \mathrm{P} / \mathrm{B})$ random copolymer PP-1 was about $3.0 \%$ and $1.1 \%$, respectively. When the third gas phase reactor was adopted to generate the E/P rubber phase, PP-2 obtained a higher ethylene content of $8.0 \%$. Meanwhile the ethylene content of PP-3 was only about $4.9 \%$ due to the homopolymerization of propylene in the two loops. The ethylene or 1-butene content of the three copolymers (PP-1/PP-2/PP-3) could be easily controlled by changing the amount of monomers in the three reactors.

The xylene soluble analysis was also conducted to characterize the atactic PP or the amorphous rubber phase, especially the $\mathrm{E} / \mathrm{P}$ rubber phase generated in the gas phase reactor. As illustrated in Table 3, the xylene soluble fraction at $25{ }^{\circ} \mathrm{C}$ of random copolymer PP- 1 was $4.8 \%$; when E/P copolymerization was conducted in the gas phase reactor, the xylene soluble fraction of PP-2 and PP-3 increased to $15.2 \%$ and $12.2 \%$, which indicated that PP- 2 had the highest $\mathrm{E} / \mathrm{P}$ rubber content. We could also see a similar trend of ethylene content in the three PPs from the IR analysis of the soluble fraction and non-soluble fraction in xylene, with ethylene content in the soluble fraction of PP-2 of about $35 \%$ and PP-3 of about $25 \%$.

\subsubsection{GPC Analysis}

From the discussion above, PP-1 was typically a random transparent copolymer, PP-2 an impact copolymer, and PP-3 an impact copolymer with high transparency. The rubber phase or the xylene soluble fraction and the rubber phase size dispersed in the PP matrix played a significant role in the mechanical and optical properties of the three PPs. In order to investigate how the rubber phase size dispersed in the PP matrix was influenced by the molecular structure of the copolymers, the molecular weights and molecular weight distributions of the three PPs and their xylene soluble fractions were determined by GPC analysis, and the GPC results are shown in Table 4 and Figure 3. 
Table 4. GPC results.

\begin{tabular}{|c|c|c|c|}
\hline Sample & $\mathrm{Mw}^{\mathrm{b}}(\mathrm{g} / \mathrm{mol})$ & $\operatorname{Mn}(\mathrm{g} / \mathrm{mol})$ & Polydispersion Index (PDI) \\
\hline PP-1 & 221,700 & 38,300 & 5.79 \\
\hline PP-1-NF *b & 175,500 & 48,500 & 3.62 \\
\hline PP-1-SF ${ }^{*} \mathrm{C}$ & 29,700 & 4500 & 6.65 \\
\hline PP-2 & 245,300 & 36,400 & 6.73 \\
\hline PP-2-NF & 183,600 & 41,800 & 4.39 \\
\hline PP-2-SF & 292,900 & 19,000 & 15.45 \\
\hline PP-3 & 228,100 & 42,800 & 5.33 \\
\hline PP-3-NF & 171,900 & 45,800 & 3.75 \\
\hline PP-3-SF & 95,800 & 9400 & 10.18 \\
\hline
\end{tabular}

a)

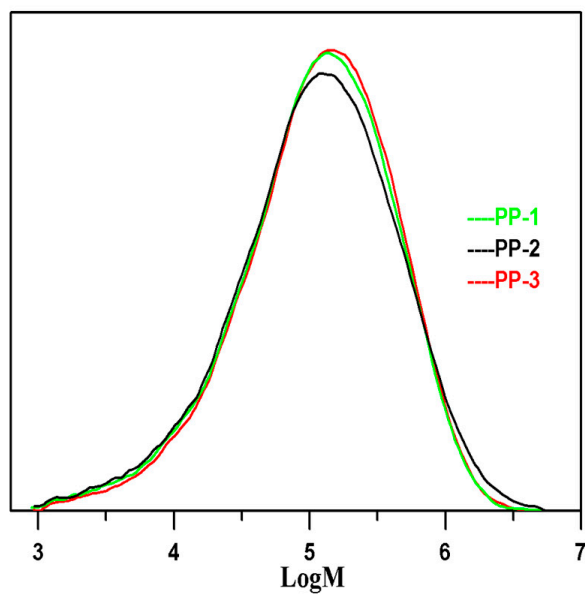

b)

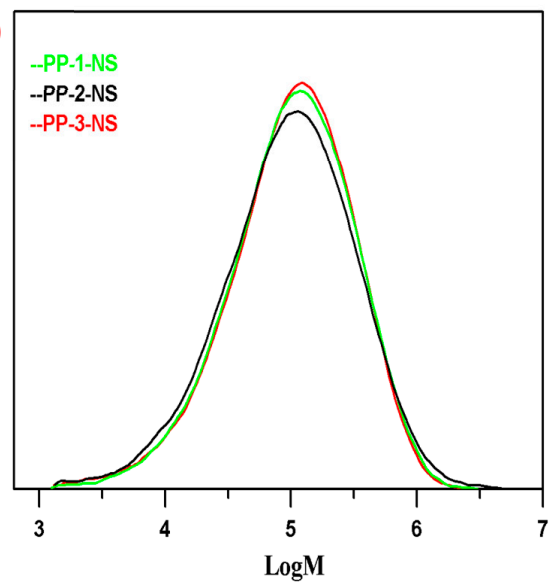

c)

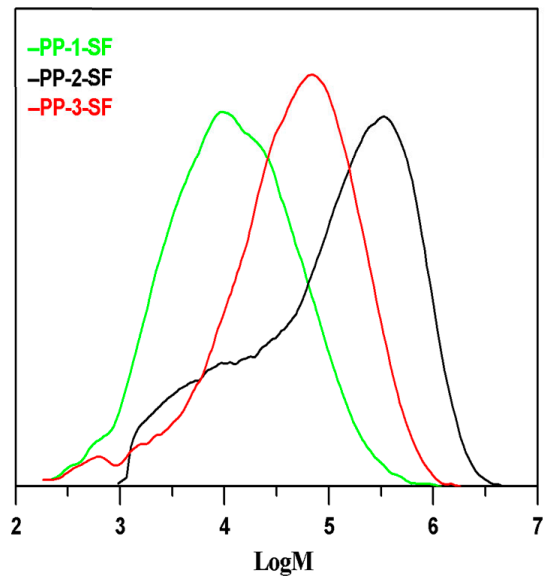

Figure 3. Molecular weight distribution curves of (a) PP samples, (b) non-soluble, and (c) soluble fractions from xylene at $25^{\circ} \mathrm{C}$.

Due to the similar melting index, the average molecular weight $(\mathrm{Mw})$ of the three PPs did not vary much, with the Mw of PP-1, PP-2, and PP-3 being 221,700 g/mol, 245,300 g/mol, and 228,100 g/mol, respectively. As seen in Figure 3, there were more small molecules with Mw below $10^{4.5}$ (Mw roughly about $32,000 \mathrm{~g} / \mathrm{mol}$ ) than in PP-1 and PP-2, which could be mainly attributed to random copolymerization conducted in the two loops. The molecular weight distribution of PP-2 (PDI $=6.73)$ was broader than PP-1 (PDI = 5.79) and PP-3 (PDI = 5.33), which could be well explained by the small molecule chains produced in the loops and the large molecules generated in the third gas phase reactor. 
The molecular weight distribution curves of the xylene soluble fractions in the three PPs would help further to illustrate the molecular chain structures produced in different reactors. The soluble fraction in xylene at $25^{\circ} \mathrm{C}$ of PP- 1 as mainly composed of small molecules with an average Mw of $29,700 \mathrm{~g} / \mathrm{mol}$; by the same token, the random E/P copolymer produced in the two loops also composed one part of the xylene soluble fraction in PP-2. As seen in Figure 3c, except for the small molecules in PP-2, the other part of xylene soluble fraction in PP-3 consisted mainly of the large E/P rubber chains. In contrast, the soluble fraction was mainly generated in the gas phase reactor, the average molecular weight of the soluble fraction in PP-3 being $95,800 \mathrm{~g} / \mathrm{mol}$, lower than that of PP-2 of 228,100 g/mol. Therefore, the molecular weight distribution of xylene soluble fraction in PP-1 (PDI $=6.65$ ) was the narrowest due to the relatively small molecule chains, and the PDI of SF in PP-2 (15.45) was the broadest because of both the random small molecules and the large E/P rubber molecules.

On the other hand, the molecular chain structure in the soluble fractions seemed to play a significant role in forming the rubber phase size when melt blending of semi-crystalline polymers and amorphous rubber chains. The amorphous polymers with small molecule chains would have better thermodynamic compatibility with the semi-crystalline polymer chains due to less chain entanglement. Consequently, the xylene soluble fractions in PP-1 had the best thermodynamic compatibility with its crystalline matrix, while PP-3 had the biggest rubber size due to poor thermodynamic compatibility. The different transparencies of the three PPs could also corroborate the difference of rubber size in different PPs, and the rubber phases of the three PPs were shown by the SEM microscope images.

\subsection{3. ${ }^{13} \mathrm{CNMR}$ Analysis}

The comonomer sequence distribution of the three PPs was characterized by ${ }^{13} \mathrm{C}$ NMR at $120{ }^{\circ} \mathrm{C}$ using $\mathrm{o}-\mathrm{C}_{6} \mathrm{H}_{4} \mathrm{Cl}_{2} / \mathrm{o}-\mathrm{C}_{6} \mathrm{D}_{4} \mathrm{Cl}_{2}(50 \% \mathrm{v} / \mathrm{v})$ as the solvent. As seen in Figure 4 , a tiny resonance peak around 10.5 ppm was observed for the random copolymer PP-1, indicating that a trace of alternating EBE (ethylene-1-butene-ethylene) sequences was present. For simplicity, 1-butene was negligible for microstructure analysis of PP-1, and only ethylene/propylene sequences were calculated for PP-1. The triad and diad sequence distributions of ethylene/propylene in the three PPs were calculated according to the method proposed by Carman and Randall et al. [35,36], and the results are presented in Table 5 . From the ${ }^{13} \mathrm{C}$ NMR results, the EEP/PEE sequence molar fractions varied from $0.37 \%$ to $9.91 \%$, which might be attributed to the different xylene soluble fractions in the three PPs.

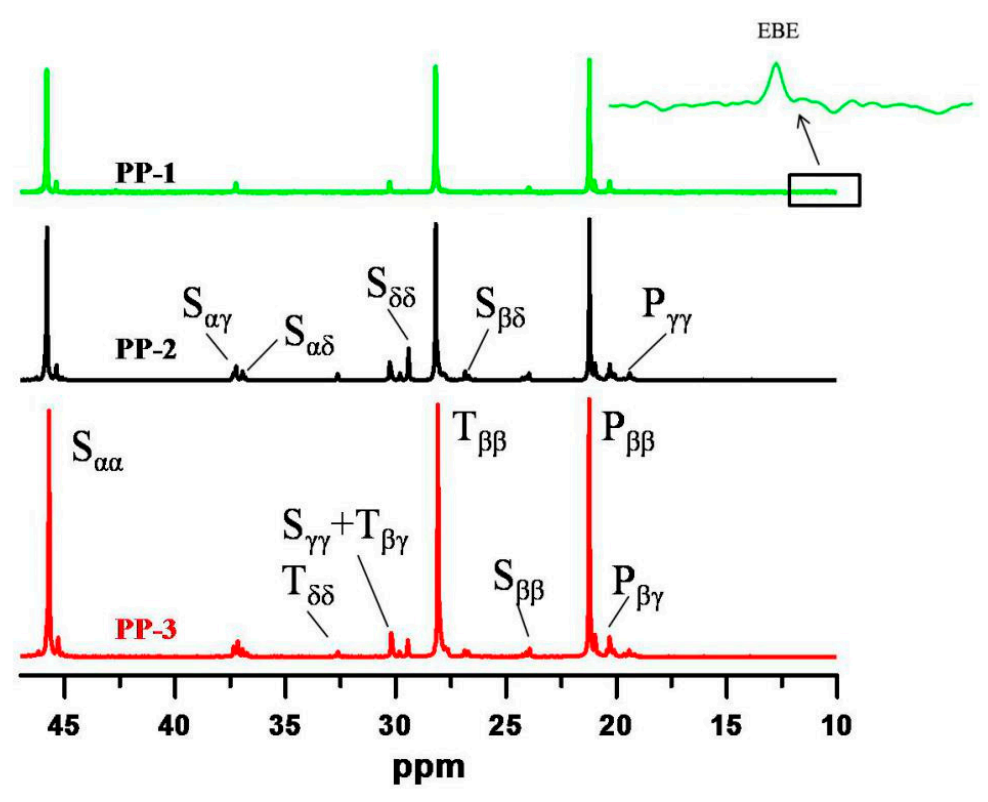

Figure 4. ${ }^{13} \mathrm{C}$ NMR spectra of the obtained samples PP-1, PP-2, and PP-3 measured at $120{ }^{\circ} \mathrm{C}$ using o- $\mathrm{C}_{6} \mathrm{H}_{4} \mathrm{Cl}_{2} / \mathrm{o}-\mathrm{C}_{6} \mathrm{D}_{4} \mathrm{Cl}_{2}(50 \% \mathrm{v} / \mathrm{v})$ as the solvent. 
Table 5. The triad and diad distributions of ethylene/propylene copolymers obtained by ${ }^{13} \mathrm{C}$ NMR.

\begin{tabular}{|c|c|c|c|c|c|c|c|c|c|}
\hline Sample & $\underset{\left.{ }^{*} \mathrm{~d}\right)}{\operatorname{EEE}(\%}$ & $\begin{array}{l}\text { EEP+PEE } \\
(\%)\end{array}$ & $\begin{array}{l}\text { PEP } \\
(\%)\end{array}$ & $\begin{array}{l}\text { EPE } \\
(\%)\end{array}$ & $\begin{array}{l}\text { EPP+PPE } \\
(\%)\end{array}$ & $\begin{array}{l}\text { PPP } \\
(\%)\end{array}$ & EE (\%) & $\begin{array}{l}E P+P E \\
(\%)\end{array}$ & PP (\%) \\
\hline PP-1 & 1.47 & 0.37 & 3.53 & 0.11 & 5.92 & 88.60 & 1.66 & 6.78 & 91.56 \\
\hline PP-2 & 2.94 & 9.91 & 4.40 & 1.47 & 15.78 & 65.50 & 7.90 & 18.71 & 73.39 \\
\hline PP-3 & 1.65 & 4.96 & 4.13 & 1.65 & 9.92 & 77.69 & 4.13 & 13.22 & 82.65 \\
\hline
\end{tabular}

${ }^{*} \mathrm{~d}$ : Molar fraction of comonomers in the three PPs determined by NMR. E: ethylene, P: propylene, EEE sequence: triple ethylene molecules in series connection. PP sequence: two propylene molecules in series connection. Similar nomenclature with other sequences.

\subsection{DSC and XRD Analysis}

Differential scanning calorimetry (DSC) results displayed (Figure 5) that the three PPs had different melting and crystallization temperatures, indicating different molecular structures. PP-3 had a melting peak around $165^{\circ} \mathrm{C}$, which was typically attributed to the highly isotactic polypropylene chains. The melting peak around $149^{\circ} \mathrm{C}$ of PP-2 belonged to the E/P random copolymer chains, and the insertion of ethylene monomer reduced the stereoregularity of the isotactic PP chains, thus decreasing the melting point. Similarly, the E/P/B random copolymer PP-1 had a melting peak around $145^{\circ} \mathrm{C}$.
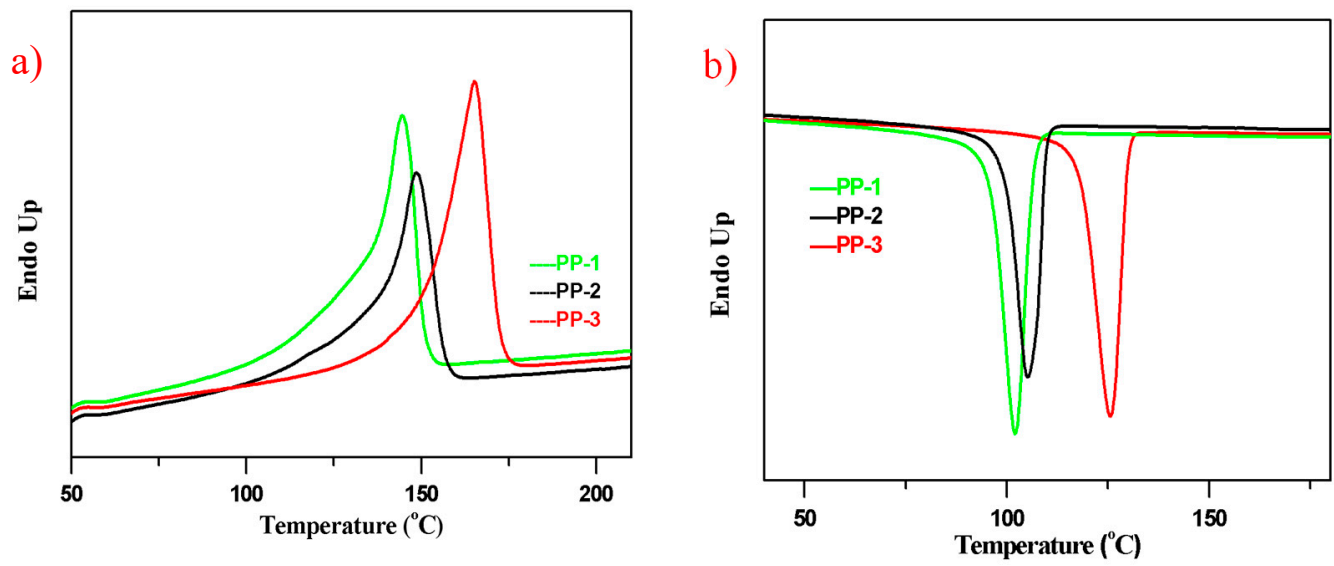

Figure 5. DSC curves for thee PP pellets at $20^{\circ} \mathrm{C} / \mathrm{min}$. (a) Melting curves; (b) cooling curves.

The crystallization peaks of PP- $1, \mathrm{PP}-2$, and PP-3 were about $102^{\circ} \mathrm{C}, 105^{\circ} \mathrm{C}$, and $125^{\circ} \mathrm{C}$, respectively.

The melting endothermic enthalpy and crystallization exothermic enthalpy data are listed in Table 6. The crystallinity of the three PPs could be estimated by their melting endothermic enthalpy. [5] From Table 6, we can see that the melting enthalpy of PP-3 had the highest value of $72.8 \mathrm{~J} / \mathrm{g}$, and PP-2 had the lowest value of $51.6 \mathrm{~J} / \mathrm{g}$. Due to their different chain stereoregularity, among the three PPs, the crystallinity of PP-3 should be the highest one, and that of PP-2 would be the lowest, which could be verified by XRD analysis with the crystallinity of PP-3 of $62.4 \%$ and of PP-2 of $51.1 \%$.

The xylene soluble fractions and non-soluble fractions of the three PPs were also characterized by the DSC analysis. As seen from Figure 6, the non-soluble fractions as the major parts of the three PPs had similar melting and cooling curves, and a slightly higher melting peak of the non-soluble fractions than their original PPs could be noticed due to their much higher chain regularity. No obvious crystallization peaks of the xylene soluble fractions in PP-2 and PP-3 were observed, which accounted for the E/P rubber phase generated in the gas phase reactor. The melting peaks of xylene soluble fractions in PP-2 and PP-3 were also lower than in PP-1. 
Table 6. DSC analysis results ${ }^{*}$.

\begin{tabular}{ccccc}
\hline Sample & Tm (Peak) ${ }^{\circ} \mathbf{C}$ & $\begin{array}{c}\Delta \mathbf{H m} \\
\mathbf{J} / \mathbf{g}\end{array}$ & $\begin{array}{c}\text { Tc (Peak) } \\
{ }^{\circ} \mathbf{C}\end{array}$ & $\begin{array}{c}\Delta \mathbf{H c} \\
\mathbf{J} / \mathbf{g}\end{array}$ \\
\hline PP-1 & 144.6 & 60.6 & 102.0 & -79.8 \\
PP-1-NF & 146.6 & 57.2 & 105.6 & -70.7 \\
PP-1-SF & 79.9 & 8.3 & 55.8 & -5.1 \\
PP-2 & 148.6 & 51.6 & 105.2 & -69.0 \\
PP-2-NF & 148.8 & 70 & 108.2 & -85.5 \\
PP-2-SF & - & - & - & - \\
PP-3 & 165.2 & 72.8 & 125.5 & -80.2 \\
PP-3-NF & 165.6 & 75.7 & 112.8 & -90.3 \\
PP-3-SF & 66.1 & 3.3 & - & - \\
\hline
\end{tabular}

${ }^{*} \mathrm{~d} 20^{\circ} \mathrm{C} / \mathrm{min}$ for pellets; $10^{\circ} \mathrm{C} / \mathrm{min}$ for xylene soluble and non-soluble fractions.
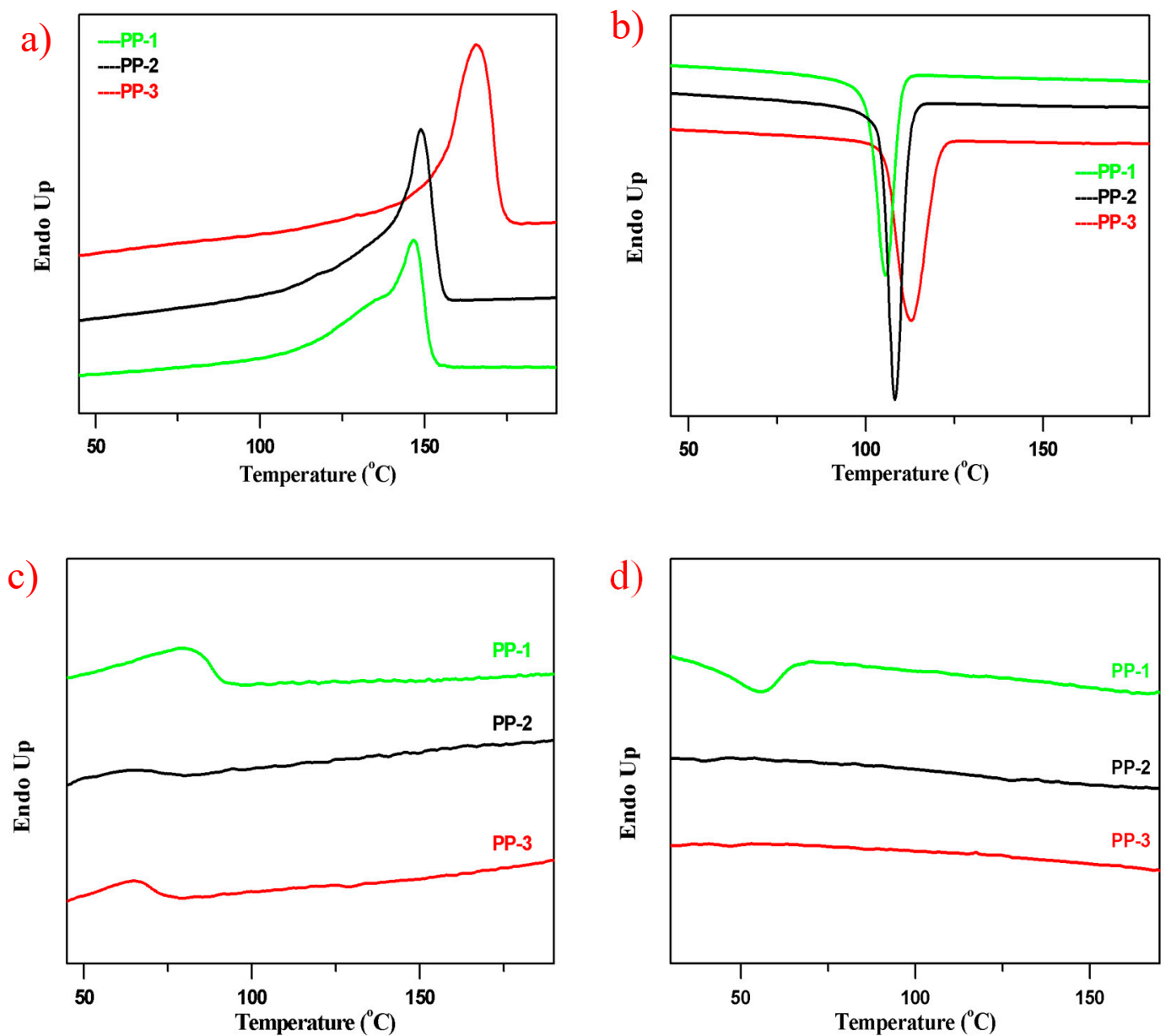

Figure 6. DSC curves of non-soluble and soluble fraction of the PP pellets from xylene at $25{ }^{\circ} \mathrm{C}$ $\left(10^{\circ} \mathrm{C} / \mathrm{min}\right)$. (a) Melting curves of non-soluble fractions of the three samples; (b) cooling curves of non-soluble fraction; (c) melting curves of soluble fraction; (d) cooling curves of soluble fraction. Endo up: the heat flow is endothermic when the peak is up.

Wide angle X-ray diffraction (WXRD) analysis was conducted to characterize the crystal type and content of the prepared PPs. From Figure 7, the diffuse peaks of $\alpha$ crystal of PP could be observed with $2 \theta$ of $14.1^{\circ}, 16.8^{\circ}$, and $18.6^{\circ}$, which were attributed to the (110), (040), and (130) crystal faces, respectively. The crystal types of the PP-1 samples with different NX 8000 content were composed mainly of $\alpha$ crystal. The crystallinity increased from $55.6 \%$ to $62.3 \%$ with the nucleating agent added in the PP-1 samples from $1500 \mathrm{ppm}$ to $3000 \mathrm{ppm}$. A tiny characteristic peak of $\beta$ crystal around $16.1^{\circ}$ of 
the (300) crystal faces could be seen in those samples. The peak area of $\beta$ crystal slightly increased when the nucleating agent was raised to $3000 \mathrm{ppm}$. Comparing the different types of PPs with the same additive formula, PP-3 had the highest crystallinity (62.4\%) and contained a tiny, but higher $\beta$ crystal content (about $0.5 \%$ ), as shown in Figure 7, which might partially explain its higher impact strength than PP- 2 with a crystallinity of $51.1 \%$ and a trace of $\beta$ crystal content. The characteristic peak around $20.5^{\circ}$ corresponding to the $\gamma$ crystal was not observed, indicating that the $\gamma$ crystal in those PPs could be neglected.
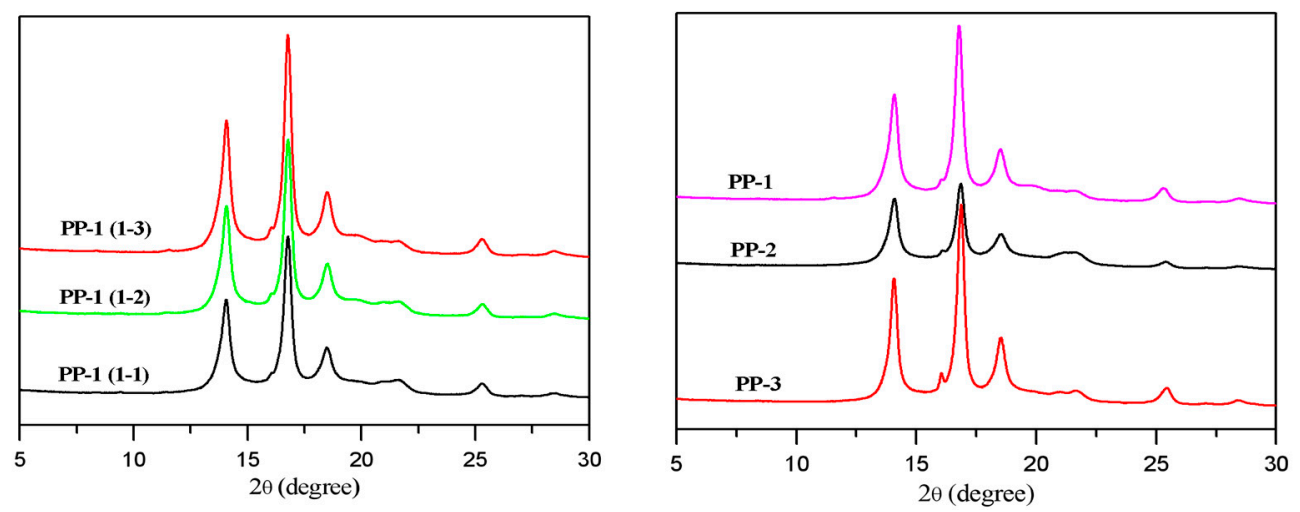

Figure 7. Wide x-ray diffraction results.

\subsection{TREF Results}

The TREF technique was also performed to analyze the chemical composition and chemical composition distributions of PPs. TREF analysis results of the three PPs are presented in Figure 8 and Table 7. The soluble fractions in TREF analysis had similar results as the xylene soluble fractions due to the similar solvent used. The random E/P/B copolymer PP-1 had a $4.0 \%$ soluble fraction due to the relatively small noncrystalline molecular chains, and PP-2 had a $17.1 \%$ soluble fraction attributed to a small part of the random E/P copolymer with small molecules produced in the loops and a majority of the large rubber molecular chains generated in the gas phase reactor. Similarly, PP-3 had a soluble fraction of $12.1 \%$, which consisted of atactic homo-polypropylene chains from the loops and rubber phase molecular chain from the gas phase reactor.

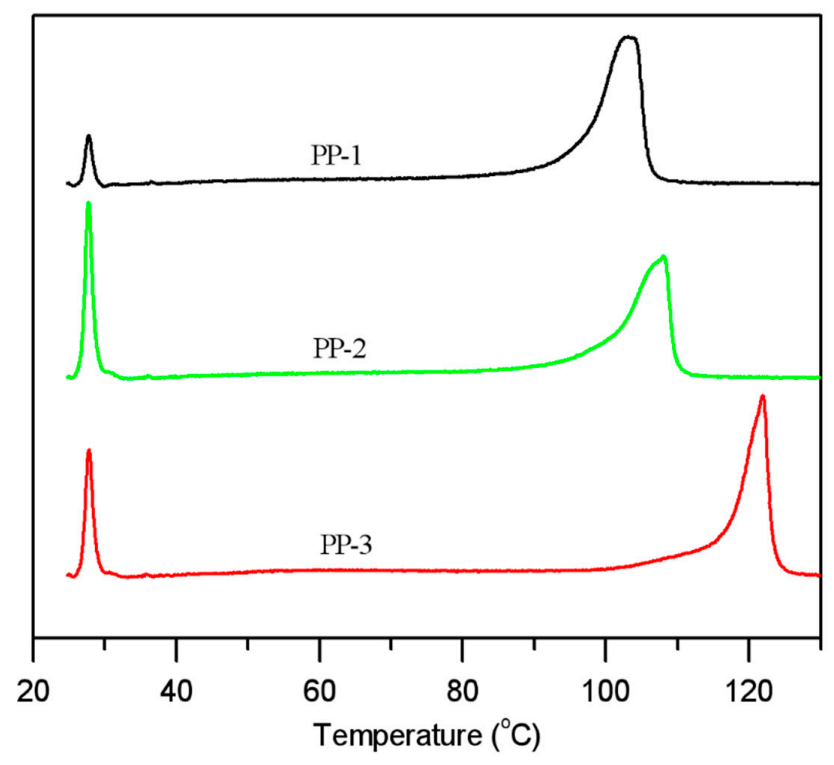

Figure 8. Temperature rising elution fractionation (TREF) results. 
Table 7. TREF analysis results.

\begin{tabular}{ccccccc}
\hline Sample & Item & Soluble Fraction (SF) & Peak 1 & Peak 2 & Peak 3 & Peak 4 \\
\hline \multirow{2}{*}{ PP-1 } & $\mathrm{T} /{ }^{\circ} \mathrm{C}$ & & 52 & 57.3 & 72.4 & 103.2 \\
& $\mathrm{Area} / \%$ & 4.0 & 2.8 & 1.6 & 2.1 & 89.5 \\
PP-2 & $\mathrm{T} /{ }^{\circ} \mathrm{C}$ & 17.1 & 57.3 & 63.9 & 72.8 & 107.4 \\
& $\mathrm{Area} / \%$ & & 3.7 & 1.9 & 1.8 & 75.4 \\
PP-3 & $\mathrm{T} /{ }^{\circ} \mathrm{C}$ & 12.1 & 62 & 77.1 & 89.5 & 121.4 \\
& $\mathrm{Area} / \%$ & 10.9 & 1.5 & 0.9 & 74.6 \\
\hline
\end{tabular}

The TREF curves also could exhibit the comonomer content distributions of copolymers and the chain regularity of homo-polypropylene. As seen from the TREF curves of PP-3, the peak around $121.4^{\circ} \mathrm{C}$ with about a $74.6 \%$ peak area was typically the highly isotactic polypropylene chains produced in the two loops, and there were also several minor peaks around $89.5^{\circ} \mathrm{C}, 77.1^{\circ} \mathrm{C}$, and $62.9^{\circ} \mathrm{C}$, which could be ascribed to less isotactic polypropylene chains and E/P copolymer chains. Normally, the crystallization capacity of polypropylene chains increased with lowered ethylene insertion content and increased chain isotacticity. When the ethylene comonomer with a low concentration was added in the two loops, ethylene would insert into the isotactic polypropylene chain to produce the random E/P copolymer with decreased crystallization capacity. As a result, PP-2 had a lower peak around $107^{\circ} \mathrm{C}$ than the isotactic polypropylene in PP-3, and the content in this peak was $75.4 \%$, which was close to that of the homopolypropylene produced in the two loops in PP-3. The polymers with high ethylene concentration generated in the gas phase reactor largely formed the rubber phase, thus being soluble in xylene and TCB at room temperature. The major peak in PP- 1 was around $103.2{ }^{\circ} \mathrm{C}$ with an $89.5 \%$ peak area, which was attributed to the insertion of ethylene and 1-butene comonomers in the isotactic polypropylene chain.

Moreover, the different ethylene contents determined by IR in the non-soluble fractions in xylene at $25{ }^{\circ} \mathrm{C}$ could be explained reasonably by the TREF curves. There were minor peaks at a lower elution temperature consisting of higher ethylene insertion into the $\mathrm{E} / \mathrm{P}$ copolymer; therefore, the ethylene content in the non-soluble fraction of PP-2 (4.6-5.8\%) could be higher than PP-1 (1.6-1.8\%) and PP-3 $(1.6-2.0 \%)$, despite the fact that the elution temperature of its major peak $\left(107.4^{\circ} \mathrm{C}\right)$ was higher than that of PP-1 $\left(103.2^{\circ} \mathrm{C}\right)$. These major elution peaks in TREF results of the three PPs were in good accordance with the melting peaks in the DSC analysis.

\subsection{Crystallization and Rubber Phase Morphology}

The isothermal crystallization of the different PPs was characterized by polarized optical microscope (POM). The POM images in Figure 9 clearly showed that the nucleating agent NX8000 had a remarkable influence on the isothermal crystallization of the three PPs by crystallization refinement. We could observe that no crystallization appeared in the three different kinds of PPs (with $200 \times$ magnification) when 3000 ppm NX8000 were added to the three PPs. In contrast, when no nucleating agent was added to PP-1, spherulites $(>1 \mu \mathrm{m})$ could be apparently observed. 

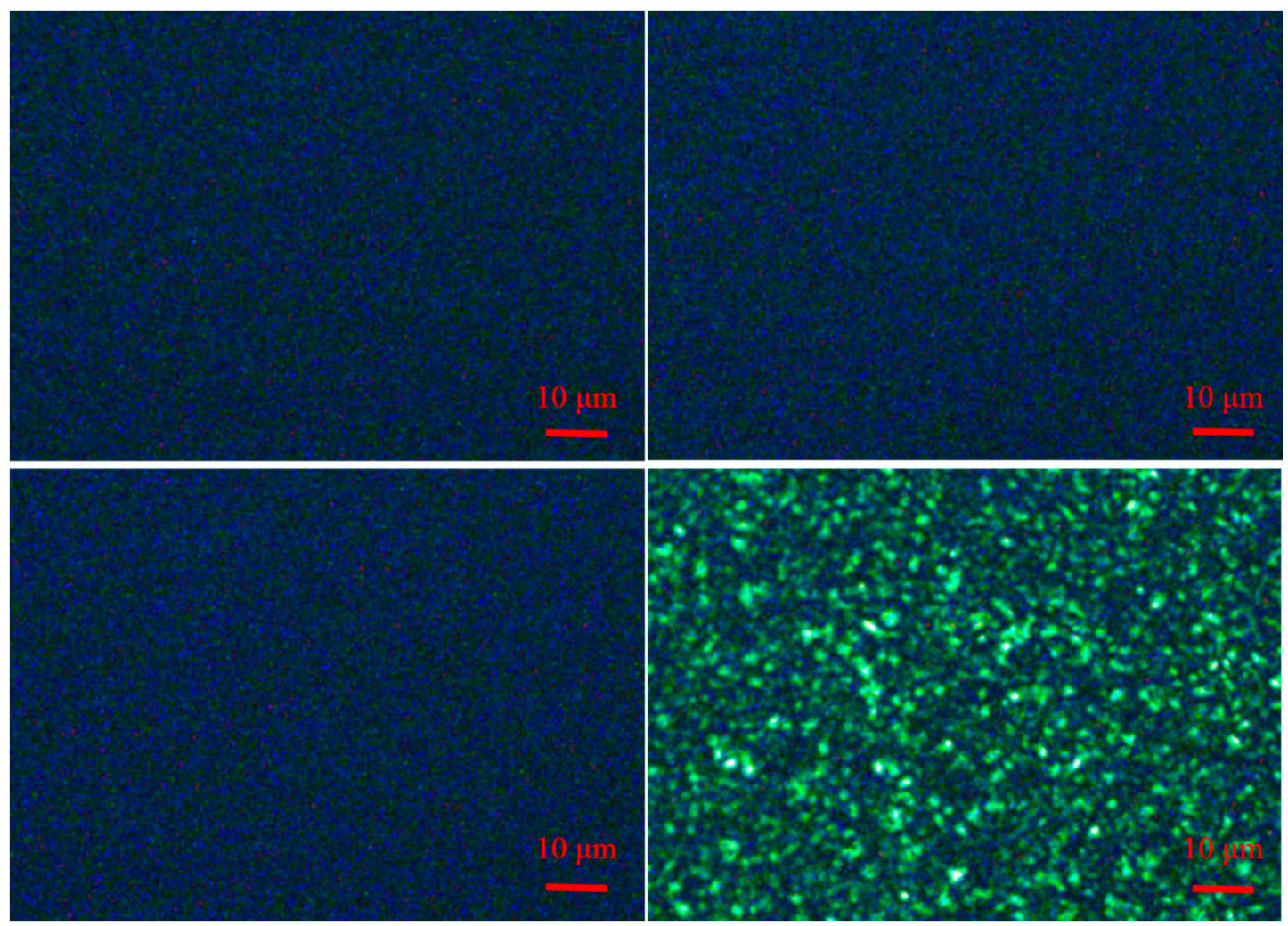

Figure 9. Polarized optical microscope images of PP: (a) PP-1, (b) PP-2, (c) PP-3 with 3000 ppm NX8000, respectively, and (d) PP-1 without the nucleating agent as a comparison. $\left(140^{\circ} \mathrm{C}, 5 \mathrm{~min}\right)$.

The rubber phase size of the three PPs was also characterized by scanning electron microscopy (SEM). The rubber phase was etched by xylene from the cryogenic fraction of injection molded bars. We could see different rubber phase sizes from the three PPs in Figure 10. Apart from a few fractions or rubber phase domains with dimensions of about $200-500 \mathrm{~nm}$, a great deal of tiny rubber holes with diameters of less than $100 \mathrm{~nm}$ could be observed on the surface of the E/P/B random copolymer PP-1. In contrast, the impact E/P copolymer PP-2 had many large rubber holes (about $1 \mu \mathrm{m}$ ) on the fraction section. Due to the massive rubber phase dispersed in the PP matrix, PP-2 obtained better impact strength than PP-1. On the other hand, the rubber phase with large domain sizes strongly scattered visible light, thus leading to poor transparency. When the rubber phase size decreased from about $1 \mu \mathrm{m}$ to about $100 \mathrm{~nm}, \mathrm{PP}-3$ obtained excellent impact strength and transparency with an evenly-dispersed rubber phase.

Combining the rubber phase sizes in the SEM images with the GPC analysis of solubility in xylene, we could reasonably infer that the rubber phase with small molecular chains had better thermal compatibility with the semi-crystalline PP matrix, and eventually led to smaller rubber phase sizes after melt blending. When the rubber phase size decreased below the half wavelength of visible light, both PP-1 and PP-3 gained excellent transparency. 

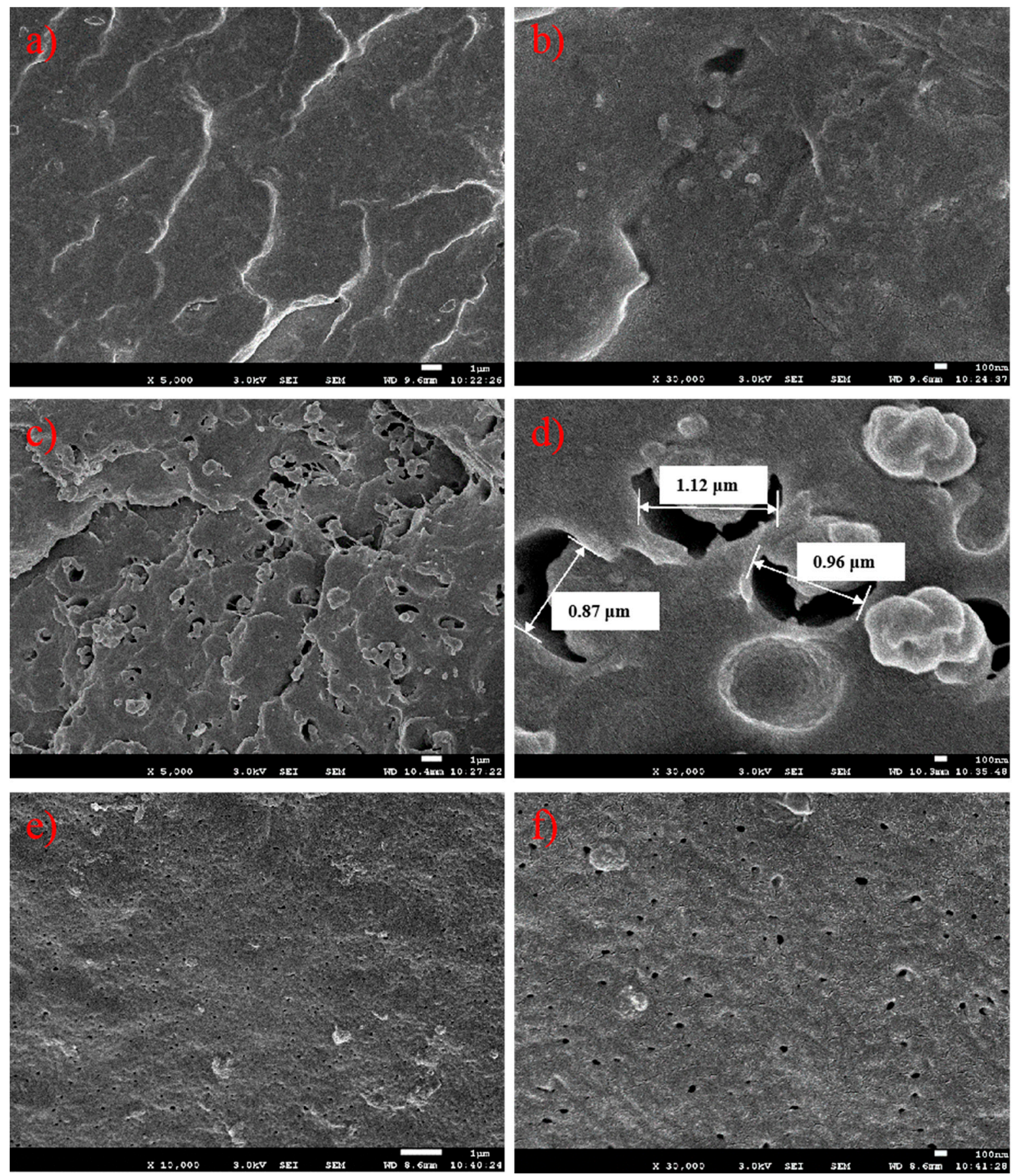

Figure 10. Scanning electron microscopy images of the three PP samples. (a) and (b) PP-1; (c) and (d) PP-2; (e) and (f) PP-3.

\section{Conclusions}

Different types of propylene-based copolymers, including random PP, impact PP, and impact PP with high clarity, could be produced in the Spheripol II process through tuning the comonomer and hydrogen concentration, combining the two loop reactors and the gas phase reactor. The molecular microstructure differences had a significant influence on the mechanical, thermal, and optical properties, as well as the meso-scale rubber phase size. The molecular structure and crystalline and rubber phase size were elucidated by the GPC, ${ }^{13}$ C NMR, TREF, DSC, XRD, POM, and SEM techniques. The results showed that the $\mathrm{E} / \mathrm{P}$ rubber phase generated in the third gas phase reactor could improve the impact 
strength dramatically from PP- 1 of $6.5 \mathrm{~kJ} / \mathrm{m}^{2}$ to PP-2 of $14.5 \mathrm{~kJ} / \mathrm{m}^{2}$. Furthermore, the molecular weight of the E/P rubber phase or xylene soluble fractions at $25^{\circ} \mathrm{C}$ could play a key role in the meso-scale dispersion of E/P rubber phase in the PP matrix. The relatively low molecular weight of the rubber phase could promote good thermal compatibility with the semi-crystalline PP chains due to less chain entanglement, resulting in a relatively small rubber phase size. Therefore, the random PP (PP-1) achieved excellent optical transparency with a haze of $12.5 \%$, while the impact PP (PP-2) looked opaque with a haze of $98.8 \%$ due to the large rubber size (about $1 \mu \mathrm{m}$ ). The impact PP with high clarity (PP-3) obtained not only good mechanical properties with a flexural modulus of $914 \mathrm{MPa}$ and an impact strength of $25.1 \mathrm{~kJ} / \mathrm{m}^{2}$, but excellent optical transparency with a haze of only $13.5 \%$, due to its even dispersion and the small dimensions of the rubber size (about $100 \mathrm{~nm}$ ) in the PP matrix. This new approach to controlling rubber phase size in the PP alloy would be a potentially important strategy for the fabrication of novel high performance PP products.

Author Contributions: Conceptualization, X.W.; formal analysis, W.K., J.F. and X.H.; investigation, X.W. and Y.X.; project administration, R.X.; writing-review \& editing, X.W. All authors have read and agreed to the published version of the manuscript.

Funding: This work was financially supported by PetroChina Refining and Petrochemicals Company (Grant Number 17-LH-06-38-01).

Acknowledgments: The financial support from PetroChina Company Limited is gratefully acknowledged. The authors would like to thank Qing-guo Wang from Qingdao University of Science and Technology (Qingdao, China) for SEM characterization and Haiyang Gao from Sun Yat-Sen University (Guangzhou, China) for conducting the ${ }^{13} \mathrm{C}$ NMR analysis.

Conflicts of Interest: The authors declare no conflict of interest.

\section{References}

1. Sauter, D.W.; Popoff, N.; Bashir, M.A.; Szeto, K.C.; Gauvin, R.M.; Delevoye, L.; Taoufik, M.; Boisson, C. The design of a bipodal bis(pentafluorophenoxy)aluminate supported on silica as an activator for ethylene polymerization using surface organometallic chemistry. Chem. Commun. 2016, 52, 4776-4779. [CrossRef] [PubMed]

2. Stürzel, M.; Mihan, S.; Mülhaupt, R. From Multisite Polymerization Catalysis to Sustainable Materials and All-Polyolefin Composites. Chem. Rev. 2016, 116, 1398-1433. [CrossRef]

3. Alt, H.G.; Köppl, A. Effffect of the nature of metallocene complexes of group IV metals on their performance in catalytic ethylene and propylene polymerization. Chem. Rev. 2000, 100, 1205-1222. [CrossRef] [PubMed]

4. Michelotti, M.; Altomare, A.; Ciardelli, F.; Roland, E. Zeolite Supported Polymerization Catalysts:Copolymerization of Ethylene and Alpha-Olefins with Metallocenes Supported on HY Zeolite. J. Mol. Catal. Part A Chem. 1998, 129, 241-248. [CrossRef]

5. Wang, X.; Han, X.; Ren, F.; Xu, R.; Bai, Y. Porous organic polymers-supported metallocene catalysts for ethylene/1-hexene copolymerization. Catalysts 2018, 8, 146. [CrossRef]

6. Yamaguchi, M.; Miyata, H.; Nitta, K.-H. Structure and properties for binary blends of isotactic polypropylene with ethylene- $\alpha$-olefin copolymer. J. Polym. Sci. B. 1997, 35, 953-961. [CrossRef]

7. Yamaguchi, M.; Nitta, K.-H.; Miyata, H.; Masuda, T. Rheological properties for binary blends of i-PP and ethylene-1-hexene copolymer. J. Appl. Polym. Sci. 1997, 63, 467-474. [CrossRef]

8. Phulkerd, P.; Funahashi, Y.; Ito, A.; Iwasaki, S.; Yamaguchi, M. Perpendicular orientation between dispersed rubber and polypropylene molecules in an oriented sheet. Polym. J. 2018, 50, 309-318. [CrossRef]

9. Geoffrey Heggs, T. Polypropylene; Wiley-VCH Verlag GmbH \& Co. KGaA: Weinheim, Germany, 2012.

10. Nwabunma, D.; Kyu, T. Polypropylene Composites; John Wiley \& Sons, Inc.: Hoboken, NJ, USA, 2008.

11. Leone, G.; Mauri, M.; Pierro, I.; Ricci, G.; Canetti, M.; Bertini, F. Polyolefifin thermoplastic elastomers from 1-octene chain-walking polymerization. Polymer 2016, 100, 37-44. [CrossRef]

12. Wang, X.; Hu, S.; Guo, Y.; Li, G.; Xu, R. Toughened high-flow polypropylene with polyolefin-based elastomers. Polymers 2019, 11, 1976. [CrossRef]

13. Baier, M.C.; Zuideveld, M.A.; Mecking, S. Post-metallocenes in the industrial production of polyolefins. Angew. Chem. Int. Ed. 2014, 53, 2-25. [CrossRef] 
14. Soares, J.B.P.; Simon, L.C. Coordination Polymerization. In Handbook of Polymer Reaction Engineering; Wiley-VCH Verlag GmbH \& Co. KGaA: Weinheim, Germany, 2005.

15. Dorini, M.; Mei, G. Spherizone technology. In Sustainable Industrial Processes; Wiley-VCH Verlag GmbH \& Co. KGaA: Weinheim, Germany, 2009.

16. Wang, X.; Han, X.; Xu, R. Versatile propylene-based polyolefifin with tunable molecular structure through tailor-made catalysts and polymerization process. In Polypropylene; Intech Open: London, UK, 2019.

17. Barbè, P.C.; Cecchin, G.; Noristi, L. The catalytic system Ti-complex/ $\mathrm{MgCl}_{2}$. Adv. Polym. Sci. 1986, 81, 1.

18. Galli, P.; Barbè, P.C.; Guidetti, G.P.; Zannetti, R.; Martorana, A.; Marigo, A.; Bergozza, M.; Fichera, A. The activation of $\mathrm{MgCl}_{2}$-supported Ziegler-Natta catalysts: a structural investigation. Eur. Polym. J. 1983, 19, 19. [CrossRef]

19. Gerbasi, R.; Marigo, A.; Martorana, A.; Zannetti, R. The crystal structure of $\alpha-\mathrm{TiCl}_{3}$ and the reticlular disorder introduced by ball-milling. Makromol. Chem. 1984, 185, 221-229. [CrossRef]

20. Kioka, M.; Kashiwa, N. Process for Producing Olefin Polymers or Copolymers and Catalyst Components Used Therefor. U.S. Patent 4,952,649, 28 Auguest 1990.

21. Mao, B.; Yang, A.; Zheng, Y.; Yang, J.; Li, Z. Catalyst System for Use in Olefinic Polymerization. Eur. Patent 0,258,485, 22 January 1992.

22. Goodall, B.L.; van der Nat, A.A.; Sjardijn, W. Olefin Polymerization Catalyst Component and Composition and Method of Preparation. U.S. Patent 4,329,253, 11 May 1982.

23. Murai, A.; Terano, M.; Kimura, K.; Inoue, M. Solid Catalyst Component for Olefin Polymerization Catalysts. U.S. Patent 4,839,321, 13 June 1989.

24. Gao, M.; Lui, H.; Li, Z.; Wang, J.; Li, T.; Wang, X.; Li, C.; Ding, C. Solid Catalyst Component for Polymerization of Olefins, Catalyst Comprising the Same and Use Thereof. U.S. Patent 20050239636, 27 October 2005.

25. Guidotti, S.; Morini, G.; Esposito, S.; Mignogna, A.; Pater, J.T.M.; Piemontesi, F.; Brita, D. Catalyst Components for the Polymerization of Olefins. U.S. Patent 20140046010, 13 Feburary 2014.

26. Guidotti, S.; Piemontesi, F.; Pater, J.T.M.; Morini, G. Catalyst Components for the Polymerization of Olefins. U.S. Patent 8,829,126, 9 September 2014.

27. Severn, J.R. Recent Developments in Supported Polyolefifin Catalysts: A Review. In Multimodal Polymers with Supported Catalysts; Springer: Berlin/Heidelberg, Germany, 2019.

28. Chen, L.; Leung, T.W.; Tao, T. Procatalyst Composition with Substitute 1,2-Phenylene Aromatic Diester Internal Donor and Method. U.S. Patent 8,288,585, 16 October 2012.

29. Van Egmond, J.W. Procatalyst Particles and Polymerization Process for Impact Copolymers. W.O. Patent 2015081254, 4 June 2015.

30. Paolo, G. The breakthrough in catalysis and processes for olefin polymerization: Innovative structures and a strategy in the materials area for the twenty-first century. Prog. Polym. Sci. 1994, 19, 959-974.

31. Covezzi, M.; Mei, G. The multizone circulating reactor technology. Chem. Eng. Sci. 2001, 56, 4059. [CrossRef]

32. Khare, N.P.; Lucas, B.; Seavey, K.C.; Seavey, K.C. Steady-State and dynamic modeling of gas-phase polypropylene processes using stirred-bed reactors. Ind. Eng. Chem. Res. 2004, 43, 884-900. [CrossRef]

33. Zhao, J.-L.; Sun, B.-J.; Gao, D.-J. Ethylene content determination in polypropylene by IR spectrum. Gansu Sci. and Technol. 2010, 26, 54-55.

34. Gao, D.-J.; Zhao, J.-L. Study on the Determination Method of Polymeric Monomer Content in Butane-ethylene-propylene Random Polypropylene. China Plast. Ind. 2017, 45, 85-88.

35. Carman, C.J.; Harrington, R.A.; Wilkes, C.E. Monomer sequence distribution in ethylene-propylene rubber measured by ${ }^{13} \mathrm{C}$ NMR. 3. Use of reaction probability model. Macromolecules 1977, 10, 536-544. [CrossRef]

36. Randall, J.C. A review of high resolution liquid ${ }^{13}$ carbon nuclear magnetic resonance characterizations of ethylene-based polymers. J. Macromol. Sci. Rev. Macromol. Chem. Phys. 1989, 29, 201-317. [CrossRef]

(C) 2020 by the authors. Licensee MDPI, Basel, Switzerland. This article is an open access article distributed under the terms and conditions of the Creative Commons Attribution (CC BY) license (http://creativecommons.org/licenses/by/4.0/). 